\title{
On the acquisition of daar and er
}

\author{
Chantal van Dijk and Peter Coopmans \\ Utrecht University
}

\begin{abstract}
Schafer \& Roeper (2000) have traced the acquisition order of the various occurrences of there in English monolingual children. One of their claims is that expletive there triggers the emergence of there as a discourse anaphor. Taking their approach as a starting point, we report here on a similar search that we have carried out on files from Dutch corpora in CHILDES, focussing on the two Dutch counterparts daar and er. Dutch children face a particular acquisition puzzle in having to deal with both of these equivalents for 'there'. Our results show that discourse anaphoric daar and er emerge prior to expletive er. This clearly contradicts Schafer \& Roeper's claim for the need of an expletive trigger. We argue instead that the discrepancy between the English and Dutch findings is caused by the much larger variety of discourse anaphoric constructions with daar and $e r$ in Dutch.
\end{abstract}

Keywords: order of acquisition, expletives, discourse anaphora, syntactic trigger

\section{Introduction}

In their study on the acquisition order of the various uses of English there, Schafer and Roeper (2000), henceforth S\&R, found that the emergence of one type of there is preceded by the emergence of another. They argued that this can best be explained in terms of successive indexing relations. In this paper we extend their empirical domain of investigation to Dutch, which has two equivalents for there: daar and er. The aim of the corpus study that we will report on was two-fold. We empirically investigated the acquisition patterns of daar and er by Dutch monolingual children, and we used this data as a testing ground for the predictions of S\&R's study and their corresponding theoretical account. We will show that there is no evidence nor any need for an account in terms of successive indexing relations. Section 2 presents an overview of the theoretical and empirical background of the acquisition of English there. Section 3 discusses the classification of Dutch 
daar and er, the criteria and corpora we have used for our study. In Section 4 we present our main observations, and in Section 5 we will discuss our results in relation to the empirical and theoretical results of S\&R's study.

\section{English there}

S\&R observe that one manifestation of there in child English is strongly referential and locative. The oral utterances in (1-2) are supported by a form of pointing or visual indication, a form of deixis. We will follow S\&R's labelling of this manifestation as 'deictic there'. (All examples in this section are taken either from Schafer \& Roeper 2000 or from Roeper \& Schafer 2002).

(1) EVE: that mom nose there. [pointing]

[Eve 1;9]

(2) JUN: there choo choo train. [looking at book] [June $1 ; 7$ ]

A second manifestation of there is referential in nature as well, though in a more or less clearly defined context of discourse. In (3-4) referential there refers to a location mentioned in the previous discourse. S\&R therefore label this type of locative there as '(discourse) anaphoric there'.

(3) FAT: it's on the cabinet.

SAR: what's my jingle bell doin $(\mathrm{g})$ up there?

(4) FAT: do you want to go down stairs?

MAR: is there a blanket down there?

The final manifestation is there in its non-referential use, 'expletive there' (5-6).

(5) APR: there was an alligator.

[April 2;9]

(6) NAO: if you go down..., there's some people.

[Naomi 3;5.6]

S\&R investigated the emergence pattern of these three manifestations of English there by looking at natural child data in about 400 files from nine children in the CHILDES corpus (MacWhinney 2000). They found a clear and consistent emergence pattern of the various kinds of there: As expected on purely intuitive grounds, the emergence of deictic there, before the age of two for most children, precedes the emergence of instances of both (discourse) anaphoric and expletive there.

Intuitively more surprising is their finding that expletive there emerges one to four months earlier than referential anaphoric there. In fact, very few examples of this (discourse) anaphor there have been found, but the ones that do occur, do so fairly late in development. This immediately raises the question what the reason for expletive tokens to emerge prior to the so-called discourse ones could be. After 
all, anaphoric there, like deictic there, has a clearly referential function, indicating a location. Expletive there has no such function, seemingly suggesting that it is more difficult to acquire. An additional act-out experiment S\&R carried out with English children supported this emergence pattern found in natural language data.

The theoretical explanation S\&R gave for their finding can be summed up in one sentence: The grammatical relation in which expletive there is involved triggers the anaphoric relation in which discourse anaphoric there is involved. In more concrete terms, the relation between there and its associate in (7) triggers the possibility and child's awareness of a relation between there and its associate in (8).

(7) There ${ }_{\mathrm{i}}$ is $[\mathrm{a} \text { man }]_{\mathrm{i}}$ in the garden.

(8) Tim put his bike [near the tree $]_{\mathrm{i}}$ and found a quarter there $\mathrm{i}_{\mathrm{i}}$.

In (7) the indexing relation captures the connection between the expletive and the postverbal subject, for the transfer of grammatical features such as agreement and case. This connection meets the requirements of a proper chain relation. In (8) there is a relation between there and its antecedent, but not in the chain sense (no c-command, no transmittance of features etc.). The grammatical relation in (7) triggers the "examination of possible other associate relations in UG, including discourse" (Schafer \& Roeper 2000:628), such as in (8).

In $S \& R$ 's view it is natural that the expletive is acquired before the discourse anaphor: Expletive there requires an associate relation as well as a chain relation. The discourse anaphor, on the other hand, does not require a chain relation. Only an associate relation is established. Hence, "the expletive interpretation entails the formal apparatus used by the discourse anaphor" (2000:629). This argument cannot be reversed, as the formal interpretation of discourse anaphora does not entail the same principles necessary for the expletive construction. That is why it can plausibly be concluded that the direction of triggering from expletive to discourse anaphor is natural. Furthermore, they argue, the expletive chain is simpler than the discourse anaphor-antecedent relation, and that it is, in fact, simpler than any other chain interpreted by the grammar.

\section{Dutch daar and er}

S\&R's claim seems to work well for English there. An interesting follow-up question would be whether cross-linguistic evidence can be found for the expletiveanaphor trigger relation. Dutch offers an interesting testing ground as this language has two equivalents for English there: the two adverbs daar and er. One of 
these can take on the function of a clear expletive: $e r$, the other one that of a deictic locative: daar.

So, the co-existence of these two Dutch 'there'-adverbs leads to such questions as:

- What is the order of emergence of daar and er?

- Do they follow separate paths of development?

- Does one trigger the other?

Once we have obtained the general picture of emergence for Dutch, we can then determine whether the observed Dutch developmental data accords with the picture emerging from S\&R's study and the explanation offered there or whether some alternative account is in order.

In our investigation aimed at testing S\&R's theory, we follow their three-way classification. The resulting overview of daar and $e r$ is given in Table 1.

Table 1. Classification

\begin{tabular}{lll}
\hline & Daar & Er \\
\hline Deictic & Yes & no \\
Expletive & No & yes \\
Anaphoric & Yes & yes \\
\hline
\end{tabular}

Although daar and er combined mirror the use of English there, each adverb on its own is clearly not fully similar to the English variant. Daar has a rather strong referential, locative interpretation. One manifestation of daar is clearly a form of deixis, hence 'deictic daar', such as in (9-10).

(9) Where is the car?

Daar.

[Pointing]

there

(10) Het boek ligt daar, op de kast

[Pointing]

the book lies there, on the cupboard

Like there, daar can be used anaphorically as well- either in a strictly locative sense (11) or in a prepositional relation (12).

(11) Locative

Gisteren ging Jan naar de winkel. Hij heeft daar een brood gekocht. yesterday went John to the store he has there a bread bought

(12) Prepositional

Op onze vakantie namen we de Bijbel mee.

on our holiday took we the Bible with 
Daar hebben we _ uit gelezen. (We hebben daaruit gelezen.)

there have we from read we have there-from read

English anaphoric there can only be found in the strictly locative sense. ${ }^{1}$ Finally, we simply take the position that daar cannot be an expletive. ${ }^{2}$

Er does not have a deictic manifestation. ${ }^{3}$ It can be used referentially, however, as a (discourse) anaphor. This can be in a strictly locative (13), a prepositional (14) or a quantitative (15) relation (cf. Bennis 1986).

(13) Locative

Jan went to the store.

Hij kocht er een boek.

he bought there a book

(14) Prepositional

Did you hear about the accident?

Ik heb er met hem over gesproken.

I have there with him about spoken

(15) Quantitative

Did you find those red puppets?

Ik heb er gisteren twee gekocht.

I have there yesterday two bought

The other manifestation of $e r$ is non-referential, as an expletive (16).

(16) Expletive

Er zit een man in de tuin.

there sits a man in the garden

In our study we adopted S\&R's method and classified uses of er and daar by Dutch children in the CHILDES corpus as either deictic, anaphoric or expletive. ${ }^{4}$ For this purpose we analysed about 150 files of five children from the Groningen corpus, as specified in Table 2 (Wijnen \& Verrips 1998).

Table 2. Overview of recordings used

\begin{tabular}{llll}
\hline & First recording & Final recording & Number of recordings \\
\hline Abel & $1 ; 10.30$ & $3 ; 04.01$ & 28 \\
Daan & $1 ; 08.21$ & $3 ; 03.30$ & 34 \\
Iris & $2 ; 01.01$ & $3 ; 06.15$ & 22 \\
Josse & $2 ; 00.07$ & $3 ; 04.17$ & 28 \\
Matthijs & $1 ; 10.13$ & $3 ; 07.02$ & 42 \\
\hline
\end{tabular}


Most utterances containing daar and er were straightforward and could be easily classified in one of the three types. Examples of clear cases of child utterances with daar are given in (17-18) and with er in (19-21):

(17) Deictic daar

MAR: wijs eens aan, waar moeten de bloemen staan? point at where must the flowers stand

CHI: daar, daar.

[Matthijs 1;10.13] there there

(18) Anaphoric (locative) daar

GER: op Texel? on Texel

GER: wat heb je allemaal gedaan daar? what have you all done there

CHI: ga kijken daar [= ik ga kijken daar]. [Josse 2;07.06] go look there [= I go look there]

(19) Anaphoric (prepositional) er

BOU: wat zeiden ze, de treinen? what said they the trains

CHI: stoom ging er toen uit. steam went there then out

[Matthijs 3;05.13]

(20) Anaphoric (quantitative) er

CHI: hee [!] mag ik die ook wat? hey may I that also what

GER: ja mag jij ook (ee)n hapje van. yes may you also an bite of

CHI: nou ik mag er eentje pakken. ow I may there one take

[Daan 3;01.14]

(21) Expletive er

CHI: enne [/] en er was een zusje. and and there was a sister

[Abel 2;11.10]

Not all occurrences of daar and er were as transparently deictic, anaphoric or expletive as in the examples above. In (22) an example is given of referential daar which might or might not have been supported by a gesture or gaze (as this is unclear from the transcription). It does refer to something in the context and it might be described as a weaker form of deixis. We have put this type of "weakly deictic uses of daar" in the broader category of deictic daar. 
(22) Weakly deictic daar

CHI: kip moet ook daar.

[Matthijs 2;10.22]

chicken must also there

The utterance in (23) is embedded in a conversation between the adult and the child about holiday pictures. In a preceding utterance the child mentions a beach visible in a picture. From the transcription it is unclear whether daar in (23) is discourse-linked to the beach mentioned earlier in the conversation, or whether daar is used deictically to refer to the beach in the picture. Such manifestations of daar were therefore neither classified as deictic nor anaphoric.

(23) Deictic/anaphoric daar

CHI: daar kun je spelen. there can you play

[Matthijs 3;04.26]

Example (24) contains an utterance where er refers to the context without an antecedent having been mentioned in the preceding discourse. In these cases it remains unclear how to classify er since we assume that er cannot be used deictically. We refer to these variations of er are to as "weakly locative er".

(24) Weakly locative er

CHI: nou ben ik $\underline{\text { r }}$ weer.

[Abel 3;01.21] now am I there again

An example of a category related to weakly locative er is given in (25). This manifestation of daar might be deictic (when supported by pointing, for example). However, it is unclear whether these types of utterances are truly deictic in nature. Therefore, these instances of daar have been categorized as "weakly locative daar".

(25) Weakly locative daar

CHI: en daar gaat (he)t weer.

and there goes it again

A final note is made here about example (26). The child is playing with a car and mentions that the car can drive off the road, without having explicitly mentioned the road earlier. Hence, there is no overt discourse linking. However, as er receives its locative interpretation from the preposition, these kinds of er have all been shared under anaphoric er.

(26) Anaphoric er without overt discourse linking

CHI: he kan er-af.

[Abel 2;04.23]

hey can there-off

In summary, when there was sufficient evidence pointing in one direction, uses of daar and er were classified as either deictic, anaphoric or expletive. When the 
evidence was indeterminate, pointing in different directions, occurrences of daar and er were assigned to the category "undecided" (Table 3 ).

Table 3. Classification daar and er

\begin{tabular}{lll}
\hline Deictic & Strong & Daar \\
& Weak & Daar \& er \\
Anaphoric & Locative & Daar \& er \\
& Prepositional & Er \\
& Quantitative & Er \\
Expletive & & Daar \\
Undecided & Deictic/anaphoric & Daar \& er \\
& Weakly locative & D
\end{tabular}

\section{Observations}

This section discusses our three main findings: daar emerges prior to er; deictic daar emerges before the discourse anaphora daar and er; and anaphoric er emerges prior to expletive er.

\subsection{Emergence of daar and er}

Table 4 displays the earliest occurrences of daar and er for the five children from the Groningen corpus. All children show a consistent pattern with daar emerging two weeks to two months prior to the first occurrences of er. Josse seems to be the only exception. However, his earliest recordings were made not until age 2;00.07 and this data does not provide evidence that he did not follow the same pattern as the other children. Furthermore, throughout the earlier recordings for all children daar is much more frequent than er.

Table 4. Age of first emergence of daar and er for each child

\begin{tabular}{lll}
\hline & Daar & Er \\
\hline Abel & $1 ; 11.12$ & $1 ; 11.26$ \\
Daan & $1 ; 10.16$ & $2 ; 00.04$ \\
Josse & $2 ; 00.07$ & $2 ; 00.07$ \\
Iris & $2 ; 08.13$ & $2 ; 09.26$ \\
Matthijs & $1 ; 10.13$ & $2 ; 00.09$ \\
\hline
\end{tabular}

In this paper we will take the development of daar and er such as found in the files of Matthijs to be more or less representative of all the children combined. For 


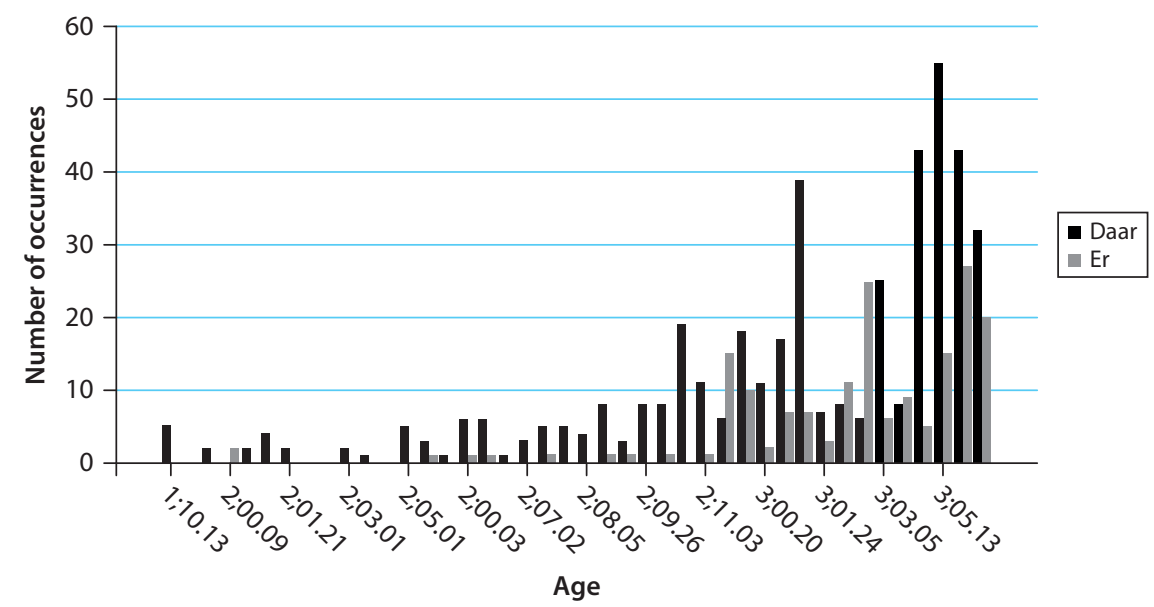

Figure 1. Number of occurrences of daar and er for Matthijs

reasons of space as well as ease of presentation, we will only show his individual development in some detail. As shown in Figure 1, daar emerges two months before the earliest occurrence of er in Matthijs' speech. Until Matthijs is 3;02, daar is much more frequent in his speech than $e r$.

\subsection{Emergence pattern of daar}

The emergence of daar was further investigated. All children show a similar and consistent pattern, as is shown in Table 5. The first manifestation is deictic daar, which is the most frequent. After three to eight months, the first instances of anaphoric prepositional daar begin to appear in the children's speech. This type of daar is also relatively frequent, especially when compared to truly locative daar, which emerges rather late - for Abel, Daan and Matthijs around the age of three - and whose use is very infrequent.

Emergence of deictic daar before (discourse) anaphoric daar is not surprising. In fact, this is to be expected as deictic daar has a clearly determinable locative interpretation, much more so than instances of anaphoric daar. This finding parallels that of S\&R's, who established that English deictic there emerges prior to other manifestations of there. Note also that deictic daar emerges before any expletive use whatsoever.

The emergence pattern of daar is further illustrated on the basis of Matthijs' data (Figure 2). Deictic daar emerges well before the first uses of anaphoric daar and its use remains dominant throughout the recordings. 
Table 5. Age of emergence of the different manifestations of daar and the total number of occurrences for each child.

\begin{tabular}{lllll}
\hline & & Deictic & Anaphoric & \\
\cline { 4 - 5 } Abel & & & Prepositional & Locative \\
\cline { 3 - 4 } Daan & First emergence & $1 ; 11.12$ & $2 ; 02.19$ & $2 ; 10.00$ \\
& Total & 166 & 37 & 11 \\
\multirow{2}{*}{ Iris } & First emergence & $1 ; 10.16$ & $2 ; 06.25$ & $3 ; 03.30$ \\
& Total & 170 & 57 & 1 \\
\multirow{2}{*}{ Josse } & First emergence & $2 ; 08.13$ & $3 ; 01.00$ & - \\
& Total & 113 & 12 & - \\
\multirow{2}{*}{ Matthijs } & First emergence & $2 ; 00.07$ & $2 ; 04.11$ & $2 ; 07.06$ \\
& Total & 127 & 53 & 18 \\
& First emergence & $1 ; 10.13$ & $2 ; 06.11$ & $3 ; 01.24$ \\
\hline
\end{tabular}

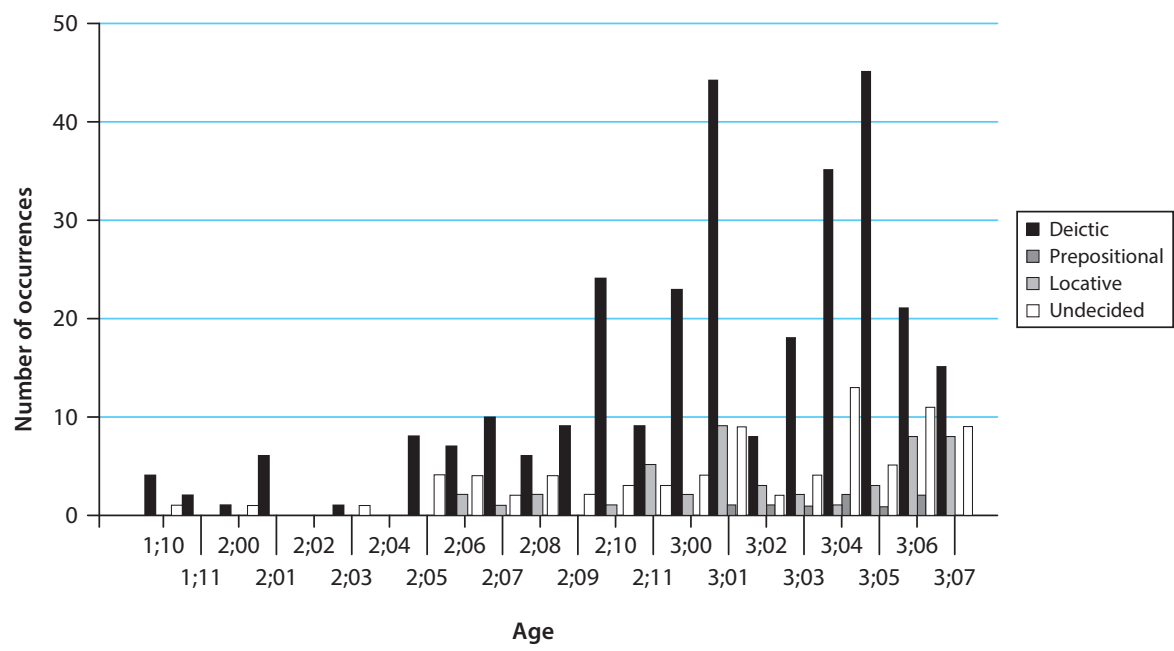

Figure 2. Number of occurrences of daar in the deictic, prepositional, locative and undecided categories in Matthijs' data

\subsection{Emergence pattern of er}

In all the children's data, prepositional er emerges prior to other instances of anaphoric er. In fact, prepositional er occurs before any other type of er (see Table 6). First uses of prepositional er in children's speech can be found around the age of two - with the exception of Iris, whose data offer only a limited number of daar and er manifestations. Furthermore, prepositional er is highly productive, compared to other uses of anaphoric er. 
Table 6. Age of emergence of the different manifestations of er and the total number of occurrences for each child

\begin{tabular}{|c|c|c|c|c|c|}
\hline & & \multirow[t]{2}{*}{ Expletive } & \multicolumn{3}{|l|}{ Anaphoric } \\
\hline & & & Prepositional & Quantitative & Locative \\
\hline \multirow[t]{2}{*}{ Abel } & First emergence & $2 ; 10.28$ & $1 ; 11.26$ & $2 ; 04.09$ & $3 ; 00.02$ \\
\hline & Total & 31 & 155 & 12 & 5 \\
\hline \multirow[t]{2}{*}{ Daan } & First emergence & $2 ; 05.11$ & $2 ; 00.04$ & $2 ; 04.28$ & $2 ; 07.15$ \\
\hline & Total & 11 & 108 & 4 & 1 \\
\hline \multirow[t]{2}{*}{ Iris } & First emergence & $3 ; 03.09$ & $2 ; 09.26$ & $3 ; 03.09$ & - \\
\hline & Total & 2 & 15 & 1 & - \\
\hline \multirow[t]{2}{*}{ Josse } & First emergence & $2 ; 03.28$ & $2 ; 00.07$ & $3 ; 00.20$ & $2 ; 09.02$ \\
\hline & Total & 25 & 158 & 5 & 8 \\
\hline \multirow[t]{2}{*}{ Matthijs } & First emergence & $2 ; 08.20$ & $2 ; 00.09$ & $3 ; 05.13$ & $3 ; 02.29$ \\
\hline & Total & 21 & 138 & 2 & 5 \\
\hline
\end{tabular}

Only a few occurrences of locative er can be found. The instances of locative er that do appear do so rather late in the children's speech. In Abel's and Matthijs' data, the first locative uses of er appear more than a year after the first emergence of prepositional er. The developments of expletive er and all instances of anaphoric er are further illustrated by Matthijs' data in Figure 3.

The emergence pattern of anaphoric locative er parallels the S\&R's findings on anaphoric there. First, manifestations of er and there are equally scarce in young children's data and appear rather late. Secondly, English expletive there and Dutch expletive er emerge prior to the locative manifestations. In Dutch this pattern does not apply to the other two instances of anaphoric er: Quantitative er is used prior

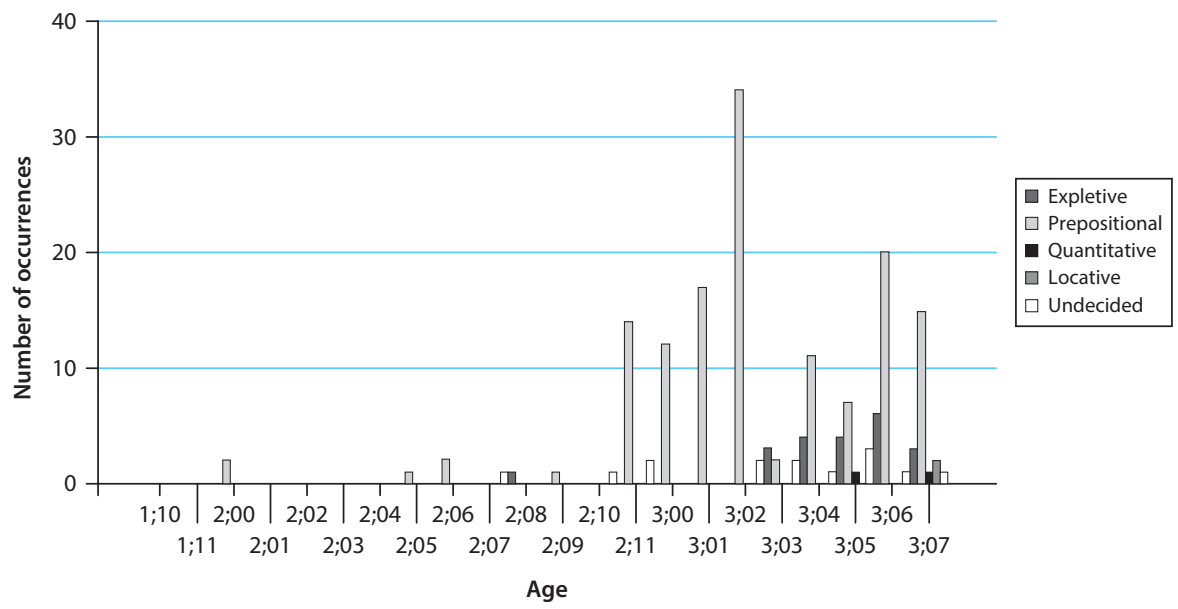

Figure 3. Number of occurrences of $e r$ in the expletive, prepositional, quantitative, locative and undecided categories in Matthijs' data 
to expletive er by Abel and Daan, and, in the data of all the children, prepositional er clearly emerges before expletive er. ${ }^{5}$ Furthermore, the use of anaphoric daar also precedes the use of expletive er, with the exception of Josse's case, as shown in Table 7.

Table 7. Age of first emergence of anaphoric er, anaphoric daar and expletive er for each child

\begin{tabular}{llll}
\hline & Anaphoric er & Anaphoric daar & Expletive er \\
\hline Abel & $1 ; 11.26$ & $2 ; 02.19$ & $2 ; 10.28$ \\
Daan & $2 ; 00.04$ & $2 ; 06.25$ & $2 ; 05.11$ \\
Iris & $2 ; 09.26$ & $3 ; 00.01$ & $3 ; 03.09$ \\
Josse & $2 ; 00.07$ & $2 ; 04.11$ & $2 ; 03.28$ \\
Matthijs & $2 ; 00.09$ & $2 ; 06.11$ & $2 ; 08.20$ \\
\hline
\end{tabular}

In summary, we have found that deictic daar emerges before other instances of daar and generally before er. This finding accords with the S\&R's results on deictic there. Our second main observation is that both anaphoric er as well as anaphoric daar are used prior to expletive er. This clearly conflicts with their suggestion that the grammatical chain in an expletive construction serves as a trigger for the emergence of a discourse link relation.

\section{Discussion}

Our first main observation that deictic daar emerges prior to any kind of er and other manifestations of daar not only accords with the findings on English there, it is also supported by van Kampen's (2010) results, who examined the use of socalled $d$-pronouns and $p$-pronouns in the natural data of one Dutch child (Sarah). She found that deictic manifestations of $d$-pronouns (die, dat and daar "that/ there") occur before the age of 2;0 in the child's recordings. Anaphoric uses of both $d$-pronouns and $p$-pronouns, among which er, did not appear until after the age of $2 ; 0$.

There exists a clear discrepancy between the English and the Dutch developmental data. In English the expletive turns out to emerge before the discourse anaphor, whereas in Dutch we find the opposite pattern. How can this difference between our study and the S\&R one be explained? Although the properties of the Dutch $r$-adverbs do differ from those of English there in certain respects, it is far from obvious, let alone attractive, that this discrepancy should be approached as a form of grammatical variation. So, what could be the reason, then, for the difference found? 6 
Firstly, one clear difference between Dutch and English makes it already difficult to adopt S\&R's claim literally. Anaphoric daar has no expletive equivalent and its anaphoric use is therefore not triggered by any phonologically similar daar. S\&R's proposal could be modified somewhat by assuming some kind of indirect triggering relation between expletive er and anaphoric daar, as in (27). This would be in line with a suggestion of $S \& R$ about triggering a family of indexing relations (2000:630-631).

(27) expletive $e r<$ anaphoric $e r<$ anaphoric daar

However, this very order has not been attested, as first uses of anaphoric daar (and anaphoric er) emerge prior to expletive er in the speech of four of the five children investigated.

The Dutch data do show a clear pattern, with children taking a step from deictic reference to anaphoric reference. The later emergence of discourse anaphora is to be expected as it requires the establishment of co-reference across clausal domains. When Dutch children start producing this kind of anaphora, they do so frequently. So, then why is it that $S \& R$ found so very few and late instances of anaphoric there in English?

A rather simple reason could be given for this discrepancy between the two languages. In Dutch there is a large variety of discourse anaphoric constructions with daar and er, namely prepositional, quantitative and locative, as discussed above. English only has one type of anaphoric there: locative there. ${ }^{7}$ Hence, S\&R only considered true cases of locative anaphoric there. This quantitative fact by itself may already account for the difference in findings.

Let us consider the other, non-truly locative, anaphoric manifestations of daar and er in more detail, such as the prepositional case in (28).

(28) Ik heb er/daar met hem over gesproken.

I have there with him about talked

In this Dutch example, although dislocated, er/daar are thematically the objects of the preposition over. This is where English could only use it/that in such an environment (about it/that). The surface manifestation of these prepositional objects in Dutch is the result of preposition stranding, whereby the moved pronominal object turns into a so-called R-pronoun. In van Riemsdijk's (1978) original account of preposition stranding in Dutch, er and daar are the left-moved counterparts of het (it) and dat (that) respectively. So, (28) is essentially the Dutch equivalent of the English example in (29):

(29) I have talked to him about it/that. 
This suggests to us that, for a proper quantitative comparison, it appears that for English the emergence of it and that as discourse anaphora should have been included in the overall view of the emergence of discourse anaphora, besides the uses of there.

The overall empirical picture has since been filled in for English on precisely this point: The emergence of anaphoric it in English. It turns out that our findings contradicting the necessity of a triggering relation find support from English too. S\&R's finding led them to predict that there should exist a similar triggering relation for other discourse anaphora, such as anaphoric it, anaphoric that, and anaphoric then. In fact, they suggested that expletive there could be a potential trigger of all discourse anaphora. Kirby and Becker (2007) tested this proposal for deictic, anaphoric and expletive $i t$, by investigating the order of emergence of the different uses of it for the same children S\&R used in their corpus study. The outcomes of this study, however, did not support the idea of a triggering relation between expletive and anaphoric it: Deictic and anaphoric it both appeared before expletive it. In fact, anaphoric it did emerge prior to expletive there as well (very much like for what we found for Dutch anaphoric er and expletive er). Neither expletive it, nor expletive there can serve as triggers for anaphoric it, and S\&R's claim is unwarranted. ${ }^{8}$

\section{Conclusion}

In this paper we have traced the development of Dutch daar and er in their early uses. More specifically, we have linked these observations to the explicit claim by Schafer \& Roeper (2000) that the grammatical chain relation necessary for the expletive construction serves as a trigger for the relation in discourse anaphora. In our study we have found that referential (deictic as well as discourse anaphoric) instances of daar and er emerge prior to expletive, non-referential, er. These findings, in part diverging from those for early English, turn out to be less of a surprising fact if we take into account the much larger variety of anaphoric uses of daar and $e r$ in Dutch compared with there in English. We conclude that there is no need for an expletive triggering link, and the Dutch results show in fact that there is none.

\section{Notes}

* We would like to thank the audience at the TIN-dag and two anonymous reviewers for their critical and insightful remarks. 
1. Modern English still has some fixed forms of the prepositional construction, surviving from older periods: thereby, therein, etc. Thanks to a reviewer for reminding us.

2. Daar always has a kind of referential interpretation. Combining it with hier 'here' is impossible, as shown in example (i). The phonologically reduced form $d^{\prime} r$ in truly existential sentences is a variant of 'er', not 'daar', as shown by examples (i-ii) combined.

(i) $\mathrm{Er} /{ }^{\star}$ Daar is hier een ongeluk gebeurd.

(ii) D'r is hier een ongeluk gebeurd.

there is here an accident happened

Interestingly, as a reviewer points out, exclamatives of the type in (iii) may constitute the limited class of exceptions to the generalisation that daar is always referential.

(iii) Daar gaat me toch een lichtje branden.

there goes me still a light-Dim burn

'Something suddenly becomes clear to me'.

3. A reviewer notes that we may find a case of deictically used er in a context where one points to a picture of a beach and says: Ik heb er fijn gezwommen. ('I had a great swim there.). Indeed, the dividing line between deictic and discourse-anaphoric is sometimes a very fine one. For the purpose of testing S\&R's theory we necessarily gloss over one or two of such subtleties.

4. S\&R also describe the results of a comprehension experiment eliciting preferences for anaphoric and expletive there. It turns out to be impossible to carry out a similar experiment in Dutch with er. However, due to space limitations we cannot discuss here the precise reasons for why this is so (but see Bennis 1986).

5. We do realise that there are limitations to this type of search in natural production data for identifying the precise moment of acquisition. After all, we do not know whether absence of earlier instances of the elements in the files investigated may have been accidental. However, since we literally applied S\&R's method, we may be confident about its comparative reliability.

6. The early manifestation of expletive there might be due to the grammatically strict requirement in English of filling the empty subject position in existential sentences. Dutch appears to be more liberal, and has alternative means of fulfilling that requirement (Olaf Koeneman, personal communication). However, a detailed comparison of first appearances of the expletive in Dutch and in English shows that they occur at about the same time.

7. An additional factor, as a reviewer points out, could be that since English is far less productive in forms of prepositional there, the only true instance of anaphoric there is the locative one, which emerges fairly late (like its Dutch counterpart, see Table 6).

8. See Grama (2011) for careful discussion of this 'anaphora puzzle'.

\section{References}

Bennis, Hans. 1986. Gaps and dummies. Dordrecht: Foris Publications. 
Grama, Ileana C. 2011. Patterns of acquisition for expletive, deictic and anaphoric it and there. ms. UiL OTS, Utrecht University.

Kampen, Jacqueline van. 2010. Anaforische middelen voor topicverschuiving. Nederlandse Taalkunde 15. 189-210.

Kirby, Susannah \& Misha Becker. 2007. Which it is it? The acquisition of referential and expletive it. Journal of Child Language 34. 571-599.

MacWhinney, Brian. 2000. The CHILDES project: Tools for analyzing talk. 3rd edn. Mahwah, NJ: Lawrence Erlbaum Associates.

Riemsdijk, Henk van. 1978. A case study in syntactic markedness: The binding nature of prepositional phrases. Lisse: Peter de Ridder Press.

Roeper, Tom \& Robin Schafer. 2002. The expletive triggers discourse anaphor. Handout presented at summer school, Düsseldorf.

Schafer, Robin \& Tom Roeper. 2000. The role of expletives in the acquisition of a discourse anaphor. In S. Catherine Howell, Sarah A. Fish \& Thea Keith-Lucas (eds.), Proceedings of the 24th Annual Boston University Conference on Language Development.Volume 2, 621-632. Somerville, MA: Cascadilla Press.

Wijnen, Frank \& Maaike Verrips. 1998. The acquisition of Dutch syntax. In Steven Gillis \& Annick De Houwer (eds.), The acquisition of Dutch, 233-299. Amsterdam: John Benjamins.

\section{Authors' addresses}

Chantal van Dijk

Utrecht University

Utrecht Institute of Linguistics OTS

Janskerkhof $13 \mathrm{a}$

3512 BL Utrecht, The Netherlands

C.N.vanDijk@uu.nl
Peter Coopmans

Utrecht University

Utrecht Institute of Linguistics OTS

Trans 10

3512 JK Utrecht, The Netherlands

p.h.a.coopmans@uu.nl 